\title{
Situating forensic traces in time
}

\begin{abstract}
Situating events and traces in time is an essential problem in investigations. To date, among the typical questions issued in forensic science, time has generally been unexplored. The reason for this can be traced to the complexity of the overall problem, addressed by several scientists in very limited projects usually stimulated by a specific case. Considering that such issues are recurrent and transcend the treatment of each trace separately, the formalisation of a framework to address dating issues in criminal investigation is undeniably needed. Through an iterative process consisting of extracting recurrent aspects discovered from the study of problems encountered by practitioners and reported in the literature, common mechanisms were extracted and provide understanding of underlying factors encountered in forensic practice. Three complementary approaches are thus highlighted and described to formalise a preliminary framework that can be applied for the dating of traces, objects, persons and indirectly events.
\end{abstract}

Keywords: forensic sciences, time, dating, age, chronology, when? 


\section{Introduction}

Forensic scientists, like archaeologists, try to reconstruct the past; to some extent, they also try to prevent future crimes. They endeavour to respond to the multiple questions that arise during the investigative process: "What? How? Why? Where? Who? When?". Among theses typical issues situating criminal activities and traces in time is a particularly important task [1]. Routinely, the investigators are confronted with the issue of time, as they are often asked one of the following questions:

- Did an event occur at a specific time? Where was a person at a specific time?

-When did an event occur? When was a trace left on the crime scene?

- How long did an event last? How old is a person?

- How often did an event occur?

- How fast did an event occur? How fast will a trace age?

- How much difference between events or traces over time?

- In what order did events occur?

- Did events occur simultaneously?

Not limited to 'when?' the time queries can thus be expressed in multiple ways [2] and clearly highlight different aspects of time such as succession, simultaneity, frequency or duration. In forensic practice however, only a few selective applications are widely conducted in routine investigation (e.g., determination of the time of death $[3,4]$ ). Considering the recurrence of such issues, it is therefore important to gain a better fundamental understanding of the dating processes. The lack of formalisation in the use of temporal information and the increasing need for such information in forensic sciences has therefore led to this paper. Through an iterative process consisting of extracting recurrent aspects discovered from the study of problems encountered by forensic practitioners and reported in the literature, common mechanisms were extracted and provided understanding of underlying factors encountered at all levels of investigation. Three complementary approaches were thus highlighted and described to formalise a preliminary framework that can be applied for the dating of traces, object, persons and indirectly events. This approach transcends the treatment of each trace separately and aims at being applied transversally to physical evidence. While clarifying the multiple issues raised by the question of time, the fundamental knowledge offered by this preliminary framework represents a new basis for future development and improvement of dating methods in forensic practice. 


\section{Dating issues}

Dating can be defined as the attribution of a relative or absolute age. It can be applied to past events, objects, people or traces. It mainly consists in the determination of the time interval, separating the elements to date and the present time and/or the determination of the relative order of past elements. Dating is widely applied and formalised in other disciplines such as archaeology [5-7]. In forensic science, the need to situate events in time is also essential but the time frame studied is generally considerably shorter (contemporaneous) and similar size errors have a larger impact. Events can generally be situated in time indirectly by the dating of traces left during the event being investigated (Figure 1). The objective is the timely extraction and interpretation of trace characteristics situated in time relevant for investigating criminal incidents and providing evidence in court. By establishing when a trace was transferred at the crime scene, it is then possible to determine the time of contact between objects and/or persons and gain valuable information about the unfolding of criminal events [8]. With this objective in mind, it is particularly important to remember that forensic traces can be very different in nature. In addition to physical traces such as fingermarks or even dead bodies, digital traces such as a computer file or mobile phone information can be studied. Moreover, events are approximately dated everyday through witness memories in the form of police statements that can also be considered as traces of the event in question. Finally, the question of the age of an object or a person can also arise in forensic science and medicine.

The main issues come from the fact that when a person commits a criminal offence, there is always a unity of time, place and action (Figure 2). The investigation will therefore aim at demonstrating this unity, by proving that a suspect was on the crime scene (i.e., unity of place) at a certain time (i.e., unity of time). The unity of action is generally inferred from the association of all observations [9]. The identification and individualisation of traces were studied and formalized early in forensic science [10] and generally lead to the unity of place. Up-to-date, the question of when a trace was left is the most difficult to answer. It is however as essential in order to link a person to a criminal activity. The relevancy of the trace is frequently challenged by the defence through the statement that the activity that generated the trace was anterior or posterior to the crime itself.

Situating events in time can also be useful in intelligence processes, such as the analysis of repetitive crimes (e.g. detection of patterns over time in high volume crimes [11]). Other dating issues in forensic science relate to the determination of the age of dead or living people. This may be useful for identification purposes (i.e., knowledge about the age of a 
unidentified body may be helpful in the identification process [12]) or for legal reasons (i.e., the penal responsibility of a minor is not the same as an adult [13]).

\section{Proposed dating framework}

In order to understand the proposed time issues, three approaches can be defined and formalised in the development of a dating methodology. The approaches will be described separately; however they are to some extent complementary and generally cannot be isolated from each other.

\section{Time tags}

The first approach focuses on inherent properties of an object or a person at the origin of the traces. These properties are named time tags. They are transferred when the trace is created and may yield different kind of temporal information (Figure 3).

Two main types of time tags may be distinguished:

- Numerical tags: These give numerical information often including time and date of creation of the traces $\left(\mathbf{t}_{\mathbf{x}}\right)$, leading to a more or less precise date or interval (i.e., absolute age). These indicators are the main source of temporal information in police investigation. They are often recovered from digital traces such as computer files, photography, mobile phone calls, gps tracing and fire alarm detectors [14,15]. In addition, fabricated objects, printed and manuscript documents also often include a date of creation, which may sometimes be hidden as a latent code [16]. Police statements issued from the memories of witnesses and investigators are also considered as numerical tags. This may be a point in time such as the date of seizure of drugs of abuse $[17,18]$ or a time range such as burglaries $[11,15,1]$ and homicide [19]. The time of the offence $\left(\mathbf{t}_{\mathbf{x}}\right)$ is then relatively imprecise and included within a time interval defined by two time tags $t_{a}$ and $t_{b}$ :

$$
t_{a}<t_{x}<t_{b}
$$

, where $t_{a}$ is for example the time when the inhabitants left their house or the last time a victim was seen (i.e., $t_{a}=$ last seen time); and $t_{c}$ is then discovery time of the burglarised house or the victim's dead body (i.e., $\mathrm{t}_{\mathrm{b}}=$ discovery or seizure time). 
When using time tags $\left(t_{x}, t_{a}, t_{b}\right)$, one must be very careful about the accuracy of the numerical information ( $\mathrm{t} \pm$ error); principally because of possible differences in time calibration of the sources (e.g., a watch is not always at exactly at the right time and different time zones may also represent a particular problem). The most practical option, if the source objects are available in the investigation, is to recalibrate the numerical indicators (for example with the atomic clock [14]) in order to minimize the uncertainty. In addition, when considering numerical time tags, one must always take into account the possibilities that such data may be more or less easily falsified.

- Contextual tags: They represent indirect contextual information from which the time can be inferred. These may also yield punctual information about the time of transfer $\left(t_{x} \pm\right.$ error $)$ or about a time interval $\left(t_{a}<t_{x}<t_{b}\right)$ during which the transfer may have taken place.

In the first case, this may be temporal information on photography or a surveillance camera. Several indications in the content of a picture may indicate when it was taken. For example, solar direction measured from the shadows in the photograph is the most precise method; however it always indicate two possible days in the year plus/minus the error [20] (e.g., the shadow orientation and length are the same the $1^{\text {st }}$ of February and the $11^{\text {th }}$ November). In order to distinguish those periods of the year, other elements of the photography can help, for example those related to the season: leaves or flowers on a tree. Additionally, meteorological information, newspaper headlines, lights in a window or stalls in front of a shop may also help determine the time of the days (e.g. sunny or cloudy time) or precise which day of the week (e.g. a weekday vs. Sunday) ${ }^{1}$. In the same way, memories of witnesses and investigators may also be in the form of contextual time tags (for example, a witness may state: 'I remember the noise of a passing train' or 'the postman delivered mail at that moment'). Furthermore, telomere length determination in a blood spots may give indication about the age of the person at the source of the trace [21,22].

Contextual tags may also yield information limited to a time interval such as manufacturing date or introduction on the market of a source object (e.g., tags introduced in ink during manufacturing may be identified in the ink entries [23]). Information about the birth date of the source person also falls in this category (e.g., in a cold case investigation, if the 'identified' person was not born yet when the crime occurred). It is then possible to determine the earliest possible date of trace transfer from this data (i.e., maximal age).

\footnotetext{
${ }^{1}$ Personal communication issued from a casework treated by Daniel Correvon, collaborator of the University of Lausanne.
} 
Instead of a temporal information $\mathbf{t}_{\mathbf{x}}$ directly linked to the transfer/creation of the trace, these time tags delineate time interval during which the trace was transferred. The time tag $t_{a}$ in equation (1) then yield then the time of fabrication, introduction on the market or birthdate of a person. These contextual tags do not vary as a function of time and are identical for all traces left by the same source object or person. They therefore yield limited temporal information and generally help to highlight anachronisms (i.e., through refutation). The renowned case of "Hilters Tagebücher" (Hitler's diaries) was resolved using the contextual tag approach. The diaries reappeared in Germany near the end of the last century. Handwriting comparison failed to detect fraud, however Julius Grant reported that fluorescent optical brighteners were found in the paper of the diaries pages [24]. In fact, in West Germany, these agents were added to paper composition only in 1948, well after Hitler's death. In this example, the contextual tags (optical brighteners) in comparison to the numerical tags (dates written in the diaries) highlighted an anachronism, because the numerical tags were indeed falsified. This is often the case in forgeries.

Exploitation of contextual time tags often required a good knowledge of the composition of traces in order to target the compounds that were time indicators. Moreover these compounds must be identifiable independently of the passing time (i.e., they should not degrade or disappear from the trace). Sometimes comprehensive knowledge of the population at the source of the traces must be available to interpret the contextual tag information correctly (for example though an ink library [25,26]). It is unknown however, to which extent the existent databases are geographically and temporally representative of the ink market, and this issue was previously questioned in court (e.g. United States of America v. Angelo Bruno et al. Crim. No. 70-12, United States District Court, E.D. Pennsylvania, Sept. 24, 1971)

\section{Aging}

In a forensic perspective, a very useful, but also very complex approach is focused on aging pathways and the kinetics of trace properties. In fact it is a central consideration, because one particularity of all individuals and materials, and as such traces, is their aging, i.e. the alteration of their properties as a function of time or/and their persistence, i.e. their disappearance as a function of time (Figure 4). As such, traces chemically and physically changes (more or less quickly) over time. The knowledge of these mechanisms and their kinetics under controlled conditions can be used to evaluate the age of traces (and should also be taken into consideration when comparing traces of unknown, potentially different, ages). 
Aging can follow many different pathways at considerably different rates. Numerous physical and chemical phenomena can be considered, such as degradation, evaporation, diffusion, migration, drying, oxidation or polymerisation. If the reaction kinetics are reproducible under controlled conditions, it is possible to estimate the time since the transfer of a trace (e.g., the time of contact between a person's finger and a surface $[27,28]$ or the time at which a gun was fired [29,30]). Chemical kinetics aim to understand the influencing factors and to develop theories in order to predict these rates. A change in concentration is measured as a function of time and represents the aging curve for a particular aging parameter inherent to the trace (Figure 5). The aging curve can then be used to extrapolate the trace age (a) and calculate the time of transfer $\left(\mathbf{t}_{\mathbf{x}}\right)$ using the following equation:

$$
t_{x}=t_{c}-a
$$

, where $t_{c}$ is the time of analysis of the trace. The rate may also vary with time and concentration and is then the instantaneous slope of an aging curve. In practice, the kinetics are often very complex because of the interactions between all constituents of a trace. Additionally, chemical and physical processes may interfere, so that more complex models generally need to be developed to describe aging reactions (e.g.,[31]).

Estimating the age of a trace is a rather difficult challenge in most cases, because aging processes are influenced by many factors apart from time, some of them considerably accelerating or inhibiting the aging. Factors of influence can be classified in three main groups: (i) the initial composition of traces (complex mixture of organic and inorganic composition), (ii) the substrates on which traces are transferred (metal, wood, plastic, paper, tissues, etc.) and (iii) the storage conditions (temperature, light, air flows, humidity, rain, etc). Obviously, the initial composition and storage conditions must themselves be inferred with some degree of uncertainty. The initial transfer of the trace will at first be influenced by most of these factors and will in fact yield the initial composition of the trace residues which represents the first point of the aging curve in Figure 5 (at time $t=0$ ). It will then subsequently influence the aging $(\mathrm{t}>0)$ conjointly with the substrate and storage conditions. 
A few practical examples of these influencing factors on aging kinetics of traces have been reported in the literature for ballpoint inks and bloodstains (e.g., effect of ink brand [32] and blood donor [33]), for fingerprints (e.g., effect of porosity of substrate [27]), gunshot residue and time of death (e.g., effect of temperature [34,12]). It is very rare that all influencing factors are comprehensively studied for a given trace type and this remains a major drawback for dating using this approach. For this reason, absolute time determination still proves to be difficult or largely impossible in casework. The objective is focused more on determining a time interval within which the transfer occurred, rather than a precise date.

\section{Chronology}

The objective of the third dating approach is to reconstruct the chronology of deposition of several traces by ordering them as a function of their relative age (Figure 6):

$$
t_{x}<t_{y}<\ldots<t_{n}
$$

, where $t_{n}$ is the time of deposition of the trace $n$. For this method the determination of a precise absolute time of deposition is not required. Moreover, it can help in monitoring criminal and security situations over time. The chronology of events can be reconstructed from the same events (i.e., one criminal act with its causes, modus operandi and effects [35,36]) or different related events (i.e., series of burglaries [11] or drug seizures [18]). Compared traces may be issued from the same source (object or person) or from different sources. For the latter, it is particularly important to insure uniform calibration of the time scale. The sequence of deposition of traces can actually be reconstructed using three different types of information (or/and combination of them):

- Superposition: Traces sometimes overlap (e.g., footprints [37] or ink strokes $[38,39]$ ) and their sequence of deposition can then be extrapolated by determination of which trace is physically placed over the others. However, this is not always as easy as it may seem (i.e., for example mixing of the ink at the crossing of lines [40]) and it cannot be applied when traces do not overlap.

- Tag sequencing: In general, calibrated numerical time tags are used to reconstruct chronologies (and detect patterns). One must be particularly careful of the 
precision/calibration of the time tags before interpreting chronologies. The error of calibration must be lower than the required dating precision. This is particularly important when several traces containing different time tags describe the same event (e.g. when dealing with multiple video footages or cameras pictures of the same event). It is also important when considering time intervals such as fabrication or seizure date. In some cases, it is not possible to reconstruct the chronology because the time interval is too large. For example, in the case of ballpoint pen inks when the investigation highlight the fact that ballpoint pen $\mathrm{x}$ was introduced on the market $\left(\mathrm{t}_{\mathrm{ax}}\right)$ before ballpoint pen $\mathrm{y}\left(\mathrm{t}_{\mathrm{ay}}\right)$ :

$$
t_{a x}<t_{a y}
$$

, it is not possible to determine if the ink entries from pen $\mathrm{x}$ were written before the ink entries from pen y. This must also be considered when ordering events by their discovery time. For example, drug intelligence and monitoring is often performed by date or year of seizure $\left(t_{c}\right)[18,41]$. While this still provides useful information about drug trafficking, it cannot be extrapolated that seizure $\mathrm{x}$ (seized at time $\mathrm{t}_{\mathrm{bx}}$ ) was manufactured or introduced in a country before seizure y (seized at time $t_{b y}$ ). However, it is very useful when the calculated interval is shorter, as is generally the case for burglaries and homicides [19,15]. Events will then be ordered using time intervals that may overlap (Figure 7).

Contextual time tags can be useful when reconstructing chronologies. In particular, from surveillance camera footage, it is possible to directly view the sequence of events, without the need to attribute calibrated numerical date to the succeeding events. An additional example is the wearing of shoe soles transferred to the traces that may approximately indicate their chronology of deposition $[42,43]$.

- Relative aging: The sequence of deposition of traces can also be determined by their relative aging states $\left(\Delta \mathrm{t}_{\mathrm{n}}\right)$. This normally simplifies the aging approach, as the absolute age (a) does not have to be calculated. This can however only be applied for traces from the same source stored in the same conditions on the same type of substrate; i.e., for traces with no variation in the influencing factors and therefore with identical aging kinetics (Figure 8). Moreover, the general evolution of the aging curve must be known as well as the measurement errors to ensure the validity of the reconstructed chronology.

\section{Summary}


The three approaches described above can be applied in practice to date many different kinds of traces (Figure 10) and indirectly events. During a criminal event, traces are transferred. Time tags inherent to the traces may give information about the time or interval of transfer (approach 1). Once transferred, the traces will age until they are collected by the investigators. The determination of their state of aging may then give useful information about their age (approach 2). Finally, the reconstruction of the transfer sequence of traces yields useful chronological information about the relative time of events (approach 3).

When applying a dating approach, one must keep in mind that the source of the traces also age and therefore several traces left by the same person or object may be of a very different nature depending on the analysed aging parameter. This consideration is also very important in the identification process. For example, DNA and fingermark minutiae do not usually change over time. However, the composition of fingermark residues and body fluids may vary throughout the life of a particular donor (this may be due to several factors such as a change in the hormonal activity [44]).

The three approaches described in Figure 9 could, to some extent, be applied to date objects (e.g. shoe: tag $=$ manufacture date; aging $=$ wearing of the sole; chronology $=$ ordering of the manufacture date) and to estimate the age of people (e.g. tag = birthdate on identity card; aging $=$ apparition of wisdom teeth or shortening of telomere length; chronology $=$ ordering people by birthdate or wisdom teeth apparition). However, in practice the 'dating' of objects and people is generally restricted to identification and legal purposes.

A few examples were selected to illustrate the description of the respective approaches along this paper and were summarised in Table 1, 2 and 3 respectively.

\section{Investigation, evaluation and intelligence}

There are substantial uncertainties and imprecisions in many delicate circumstances when considering dating issues. Much work is still required in order to develop a methodology that integrates the solid treatment of these uncertainties. However, depending on the type of inference, the nature of the decision making process it supports, and the proposed framework, possible directions for how to effectively use the information and accommodate with its imperfections can be given. 
Situating a trace in time serves the three main purposes of forensic sciences: as information to help investigators [45,46,1], as evidence in court [31], and also in support to more proactive policing framework such as intelligence-led approaches (even for health or other security issues) $[47,48]$. The interpretation of traces and dissemination of the information both highly depend on the decision-making process which goes well beyond a court trial.

Dating particularly through time tags is often applied to aid investigation. During the investigative process, all information is integrated to form hypotheses and propositions, test and refute them in a complex reasoning pattern where time is frequently of crucial importance (combined with spatial and relational information). For example, when a suspect is arrested, his mobile phone information will give the position, time and duration of calls (Figure 7). The dating of criminal events may then be compared to this information in order to link the calls to the events being investigated [15]. The investigators are generally aware of the limitations of the approaches because of imprecisions in the determination of time intervals and possibilities of falsification. The aim here is to rapidly build a list of promising cases that investigators can use to interview the suspect. On this basis, the investigator will envisage a series of other operations aiming to test the hypothesis of the suspect's participation to the criminal events: e.g. check suspects alibi using several sources of information or compare the traces collected at the scene with the suspect or her accessories.

On the other hand, dating methodologies are frequently used to provide court evidence. The issues were most particularly discussed in the questioned document field [49,50], and to some extent in other field such as fingermarks [51], blood dating [52] or estimation of people age [13]. When working for the court, scientists therefore often tried to circumvent interpretation difficulties mainly due to influence factors by proposing decision thresholds that should ideally be valid for all encountered situations [53,32]. However, a probabilistic answer based on Bayesian inference of sources, is now generally considered the better approach in forensic sciences $[54,55]$. Following this guidance, recent works proposed the use of likelihood ratio (LR) to interpret dating evidence for inks [31,56], gunshot residues [57] and a person's age [13] : 


$$
L R=\frac{P\left(C \mid t_{p}\right)}{P\left(C \mid t_{d}\right)}
$$

, where $\mathrm{C}$ is the dating evidence obtained through the analysis (performed at time $t_{c}$ ), and $t_{p}$ and $t_{d}$ are the alternative hypotheses about the time of deposition $t_{x}$ proposed by the defence and the prosecution respectively. The likelihood ratio allows the comparison of the probability of the dating evidence $(C)$ given the trace was created at time $t_{p}$ (e.g., during the crime) to the probability of this same dating evidence given the trace was left at a different time $t_{a}$ (e.g., before or after the crime). Consideration of two alternative hypotheses allows for a balanced evaluation of the evidence. The interpretation of the results should however be validated, as well as the dating methodologies, in order to see if it is reliable for presentation of dating evidence in court.

This is again much different when time tags are used to gain useful intelligence and monitor particular situations through reconstruction of the chronologies. The detection of shoemarks in burglaries were, for example, used to highlight when the same pattern was detected more frequently or in a specific region [58]. However, when a "hot spot" or a tendency (concentration or increase in the occurrence of a certain sole pattern) are detected, there is no intent to prove the activity of a serial burglar: the hot spot or tendency may have another cause such as the introduction on the market of soles with a new pattern. Thus, it rather point to a set of promising cases to be analysed further with other sources or information such as modus operandi $[11,58]$. This analysis may or may not lead to the conclusion of existence of the repetition of crimes perpetrated by the same offender. Another important question in crime analysis is the determination of the global time pattern leading to the time when crimes preferably occurs (e.g. the repetition of burglaries of a certain type at a particular time of the day). The more precisely the time pattern can be determined, the more efficient the involvement of resources will be deployed to respond to it. In this circumstance, the global time pattern can be estimated by using different methods. For example, the Equal Opportunity method is frequently used for this purpose. It consists of considering that each burglary case has a uniform probability of having been perpetrated anytime in the time interval between tags $t_{a}$ and $t_{b}$. Then all the densities of probability built from each case are combined to form the global pattern (the detailed presentation of the method is out of the scope of this paper, see [59] for illustrations). This is only an estimation that even tolerates some limited errors in 
regards to the aim of the analysis. When dealing with several hundreds of burglaries, errors on a few cases will not change the global time pattern, and consequently intelligence that will help responding to the phenomena. The synthesis is more important than detailed information of each specific case in a series.

Our framework regroups three types of inference useful either in an investigative, evaluative or crime intelligence context. It helps clarify what is done intuitively today and thus shapes reasoning processes when dealing with practical cases, gives direction for relevant research programmes or has the potential to be used for educational purposes as a methodology. In particular, it points where models of interpretation deserve to be consolidated in regards to the decision making process the information serves.

\section{Conclusion}

Forensic science reconstructs the past, based on evidence of a physical nature that are signs indicative or associated with criminal events. The importance of time in forensic science is therefore not questionable and situating events in time is generally acknowledged as a fundamental issue. In this article, three main approaches could thus be extracted and were described to situate traces, people and events in time: (1) time tags, (2) aging, and (3) chronologies. Their formalisation may help scientists and investigators to apply them more consciously in practice and in a complementary way. This preliminary framework is therefore a useful first step towards a global methodology for approaching dating issues in forensic science.

In addition, it was observed that some dating methodologies are in fact applied everyday, while others are less known and/or less developed. Thus time tags and chronologies are routinely used in investigations, however, they are almost absent from the forensic literature. Therefore, it was particularly useful to formalise and include them in the preliminary dating framework. On the other hand, the aging approach is not commonly used in practice because of unresolved reliability issues. Nevertheless, it is the subject of many scientific publications. The aging of traces involves complex processes that remain poorly understood. Much more research needs to be conducted on dating through estimation of aging state of traces. 


\section{Acknowledgment}

The authors wish to thank Aimee Llyod (from the University of Technology in Sydney) for proofreading this manuscript. We also want to acknowledge Prof. Olivier Delémont, Dr. Quentin Rossy, Aline Girod, Agnès Koenig and Matteo Gallidabino (from the University of Lausanne) for their useful contributions in the discussions that have led to this article.

This work has been kindly supported by the Swiss National Science Foundation (Fund No. PP00P1_123358/1). 


\section{References}

[1] P. Margot, A question of time. Science \& Justice 40 (2) (2000) 64-71.

[2] A. MacEachren, Chapter 7: A lexical approach to map representation, How maps work - Representation, visualization, and design, The Guilford Press, NewYork, 2004, pp. 315-317.

[3] M. Kaliszan, R. Hauser, G. Kernbach-Wighton, Estimation of the time of death based on the assessment of post mortem processes with emphasis on body cooling. Legal Medicine 11 (2009) 111-117.

[4] C. Wyss, D. Cherix, Traité d'entomologie forensique - Les insectes sur la scène de crime, Lausanne, 2006.

[5] J.W. Michels, Dating methods. Annual Review of Anthropology 1 (1972) 113-126.

[6] H. Schwarcz, Chronometric Dating in Archeology: A Review. Accounts of Chemical Research 35 (2002) 637-643.

[7] J. Rossignol, L. Wandsnider (Eds.), Space, Time, and Archeological Landscapes, Plenum Press, New York, NewYork, 1992.

[8] O. Ribaux, A. Baylon, E. Lock, O. Delémont, C. Roux, C. Zingg, P. Margot, Intelligence-led crime scene processing. Part II: Intelligence and crime scence examination. Forensic Science International 199 (2010) 63-71.

[9] J.-C. Martin, O. Delémont, P. Esseiva, A. Jacquat, Investigation de scène de crime fixation de l'état des lieux et traitement des traces d'objets. Presses polytechniques et universitaires romandes, collection sciences forensiques, Lausanne (2010) pp. 14-15.

[10] P.L. Kirk, The ontogeny of criminalistics. Journal of Criminal Law, Criminology and Police Science 54 (1963) 235-238.

[11] O. Ribaux, P. Margot, Inference structures for crime analysis and intelligence: the example of burglary using forensic science data. Forensic Science International 100 (1999) 193-210.

[12] N. Lynnerup, H. Kjeldsen, R. Zweihoff, S. Heegaard, C. Jacobsen, J. Heinemeier, Ascertaining year of birth/age at death in forensic cases: A review of conventional methods and methods allowing for absolute chronology. Forensic Science International 201 (2010) 74-78.

[13] A. Schmeling, G. Geserick, W. Reisinger, A. Olze, Age estimation. Forensic Science International 165 (2007) 178-181.

[14] Fire at the detention center Schiphol Oost, Dutch Safety Board, The Hague, (26.10.2005),

http://www.onderzoeksraad.nl/docs/rapporten/report_fire_schiphol_oost.pdf.

[15] S. Birrer, A.-L. Terrettaz-Zufferey, Croisement spatial et temporel de données issues d'activités délictueuses et d'appareils permettant une géolocalisation. Revue internationale de criminologie et de police technique et scientifique LXI (4) (2008) 481-500.

[16] R. Khamsi, Laser printer dot code revealed. Nature News http://www.nature.com/news/2005/051019/full/news051017-9.html (2005) last access: 20.05.2011.

[17] C. Weyermann, P. Esseiva, F. Anglada, I. Baer, M. Bovens, C. Zingg, Le potentiel des données collectées sur les comprimés Ecstasy saisis en Suisse: (1) Tendance du marché clandestin. Revue internationale de criminologie et de police technique et scientifique 2007 (1) (2007) 103-115. 
[18] P. Esseiva, S. Ioset, F. Anglada, L. Gaste, O. Ribaux, P. Margot, A. Gallusser, A. Biedermann, Y. Specht, E. Ottinger, Forensic drug intelligence: an important tool in law enforcement. Forensic Science International 167 (2-3) (2007) 242-246.

[19] S. Kind, The Scientific Investigation of Crime, Forensic Science Services, Harrogate, England, 1987, p. 375.

[20] J.A. Levi, Y. Novoselsky, N. Levin, N. Volkov, Determining the Time and Day of Photography. Journal of Forensic Sciences 45 (1) (2000) 153-157.

[21] S. Hewakapuge, R.A.H. van Oorschot, P. Lewandowski, S. Baindur-Hudson, Investigation of telomere lengths measurement by quantitative real-time PCR to predict age. Legal Medicine 10 (2008) 236-242.

[22] S. Mayer, S. Brüderlein, S. Perner, I. Waibel, A. Holdenried, N. Ciloglu, C. Hasel, T. Mattfeldt, K.V. Nielsen, P. Möller, Sex-specific telomere length profi les and agedependent erosion dynamics of individual chromosome arms in humans. Cytogenet Genome Res 112 (2006) 194-201.

[23] A.A. Cantu, A Sketch of Analytical Methods For Document Dating. Part I. The Static Approach: Determining Age Independent Analytical Profiles. International Journal of Forensic Document Examiners 1 (1) (1995) 40-51.

[24] J. Grant, The Diaries of Adolf Hitler. Journal of the Forensic Science Society, Science \& Justice 25 (1985) 189.

[25] J.H. Bügler, M. Graydon, B. Ostrum, The practical use of the Munich ink reference collection in daily casework, 6th European Document Examiners Working Group (EDEWG) Conference, Dubrovnik, Croatia, 2010.

[26] C. Neumann, R. Ramotowski, T. Genessay, Forensic examination of ink by highperformance thin layer chromatography-The United States Secret Service Digital Ink Library. Journal of Chromatography A 1218 (2011) 2793-2811.

[27] C. Weyermann, C. Roux, C. Champod, Initial Results on the Composition of Fingerprints and its Evolution as a Function of Time by GC/MS Analysis. Journal of Forensic Sciences 56 (1) (2011) 102-108.

[28] K. Baniuk, Determination of Age of Fingerprints. Forensic Science International 46 (1990) 133-137.

[29] C. Weyermann, V. Belaud, F. Riva, F. Romolo, Analysis of organic volatile residues in 9 mm spent cartridges. Forensic Science International 186 (1-3) (2009) 29-35.

[30] J. Andrasko, T. Norberg, S. Stahling, Time Since Discharge of Shotguns. Journal of Forensic Sciences 43 (5) (1998) 1005-1015.

[31] C. Weyermann, J. Almog, J.H. Bügler, A.A. Cantu, Minimum requirements for application of ink dating methods based on solvent analysis in casework. Forensic Science International 210 (1-3) (2011) 52-62.

[32] J.H. Bügler, H. Buchner, A. Dallmayer, Age Determination of Ballpoint Pen Ink by Thermal Desorption and Gas Chromatography-Mass Spectrometry. Journal of Forensic Sciences 53 (4) (2008) 982-988.

[33] S. Anderson, B. Howard, G. Hobbs, C. Bishop, A method for determining the age of a bloodstain. Forensic Science International 148 (2005) 37-45.

[34] J. Andrasko, S. Stahling, Time Since Discharge of Spent Cartridges. Journal of Forensic Sciences 44 (3) (1999) 487-495.

[35] S. Kind, Chapter 5: Time and Sequence, The Scientific Investigation of Crime, Forensic Science Services, Harrogate, England, 1987, pp. 106-389.

[36] A. Girod, C. Champod, O. Ribaux, Chapitre 3: Démarche et schémas d'utilisation, Traces de souliers, Collection Sciences Forensiques, Presses polytechniques et universitaires romandes, 2008, pp. 23-26. 
[37] S. Kind, The Scientific Investigation of Crime, Forensic Science Services, Harrogate, England, 1987, p. 55.

[38] G. Poulin, Establishing the sequence of strokes: the state of the art. International Journal of Forensic Document Examiners 2 (16-32) (1996).

[39] G. Schirripa Spagnolo, Potentiality of 3D laser profilometry to determine the sequence of homogenous crossing lines on questioned documents. Forensic Science International 164 (2) (2006) 102-109.

[40] C. Weyermann, Mass Spectrometric Investigation of the Aging Processes of Ballpoint Ink for the Examination of Questioned Documents. p.114, Faculty of Biology and Chemistry, Justus-Liebig University, 2005. Available on-line: http://geb.unigiessen.de/geb/volltexte/2006/3044/

[41] C. Weyermann, P. Esseiva, F. Anglada, M. Bovens, C. Zingg, Le potentiel des données collectées sur les comprimés Ecstasy saisis en Suisse: (2)Renseignement tactique et opérationnel. Revue internationale de criminologie et de police technique et scientifique 2007 (2) (2007) 236-247.

[42] M. Tart, J. Adams, A. Downey, Feathering, transient wear features and wear pattern analysis: a study of the progressive wear of training shoes outsoles. Information Bulletin for Shoeprint/Toolmark Examiners. Proceedings of the 2nd European SP/TM Conference 4 (1) (1998) 51-68.

[43] A. Girod, C. Champod, O. Ribaux, Traces de souliers, Collection Sciences Forensiques, Presses polytechniques et universitaires romandes, 2008, pp. 251-278.

[44] M. Buchanan, K. Asano, A. Bohanon, Chemical characterization of fingerprints from adults and children. SPIE 2941 (1997) 89-95.

[45] J.-L. Gremaud, Processus de reconnaissance et d'identification de personnes décédées, $\mathrm{PhD}$ Thesis, Institut de Police Scientifique, University of Lausanne, 2010, http://www.unil.ch/webdav/site/esc/shared/These_Gremaud.pdf (last access july 2011).

[46] O. Ribaux, S. Walsh, P. Margot, The contribution of forensic science to crime analysis and investigation: Forensic intelligence. Forensic Science International 156 (2006) 171-181.

[47] United Nations Office on Drugs and Crime (ONUDC). WORLD DRUG REPORT 2010. United Nations Publication, Sales No. E.10.XI.13, http://www.unodc.org/documents/wdr/WDR_2010/World_Drug_Report_2010_lores.pdf (last access: July 2011), NewYork, 2010.

[48] O. Ribaux, A. Baylon, C. Roux, O. Delémont, E. Lock, C. Zingg, P. Margot, Intelligence-led crime scene processing. Part I: Forensic intelligence. Forensic Science International 195 (2010) 10-16.

[49] J.E. Starrs, Forensic science in law enforcement - ink analysis. The Scientific Sleuthing Newsletter 18 (4) (1994) 11.

[50] J.E. Starrs, Ink Dating Up-Dated and Up-Ended. International Journal of Forensic Document Examiners 1 (1) (1995) 3 - 5.

[51] K. Wertheim, Fingerprint Age Determination: Is There Any Hope? Journal of Forensic Identification 53 (1) (2003) 42-49.

[52] R.H. Bremmer, Forensic Quest for age determination of bloodstains. Forensic Science International, In Press (2011).

[53] V.N. Aginsky, Dating and Characterizing Writing, Stamp, Pad and Jet Printer Inks by Gas Chromatography / Mass Spectrometry. International Journal of Forensic Document Examiners 2 (2) (1996) 103-116.

[54] I.W. Evett, Bayesian inference and forensic science: problems and perspectives. The Statistician 36 (1987) 99-105. 
[55] R. Cook, I.W. Evett, G. Jackson, P.J. Jones, J.A. Lambert, A model for case assessment and interpretation. Science \& Justice 38 (3) (1998) 151-156.

[56] C. Weyermann, B. Schiffer, P. Margot, A logical framework to ballpoint ink dating interpretation. Science \& Justice 48 (3) (2008) 118-125.

[57] M. Gallidabino, C. Weyermann, F. Romolo, F. Taroni, A logical approach for evidential assessment in cases involving the estimation of the time since discharge of firearms. Forensic Science International submitted June (2011).

[58] O. Ribaux, A. Girod, S. Walsh, P. Margot, S. Mizrahi, V. Clivaz, Forensic Intelligence and Crime Analysis. Probability, Law and Risk 2(2) (2003) 47-60.

[59] S. Gottlieb, S. Arenberg, Crime Analysis: From First Report to Final Arrest. , Alpha publishing, Montclair, Californie, 1998. 
Figure 1 - Resulting from a criminal situation (at time $t_{x}$ ) traces can later be collected (at time $t_{b}$ ) and analysed (at time $t_{c}$ ) through the investigative process. Their interpretation may serve as evidence to reconstruct the chronology of events that happened before, during and after the crime.

Figure 2 - When a person commits a criminal offense, there is a unity of time, place and action. The investigation will aim at demonstrating this unity, by proving that a suspect was on the crime scene (i.e., unity of place) at a certain time (i.e., unity of time). The unity of action generally results from the reasoning.

Figure 3 - The first approach for dating traces results from the recovery of time tags transferred with the trace at the time $\boldsymbol{t}_{x}$ during the investigated event.

Figure 4 - The second approach for dating traces is based on the determination of the state of aging of a trace, $\boldsymbol{a}$ (i.e., the age of the trace $x$ ).

Figure 5 - Example of an aging curve following an exponential decrease: an aging parameter $\boldsymbol{p}$ is plotted as a function of the time $\boldsymbol{t}$ (time scales may vary significantly in function of the rate of aging of selected parameter e.g. hour, day, year unities). In an investigation, the analysis of the trace at time $\left(t_{c}\right)$ would yield the value $p_{c}$. The aging curve can then be used to extrapolate the trace age $(a)$ and calculate the time of transfer $\left(\boldsymbol{t}_{\boldsymbol{x}}\right)$ with the following equation: $\boldsymbol{t}_{\boldsymbol{x}}=t_{c}-a$.

Figure 6 - The third approach for dating traces reconstruct the chronology of events by comparing the absolute or relative sequence of deposition of different traces (i.e., $\boldsymbol{t}_{\boldsymbol{x}}<\boldsymbol{t}_{\boldsymbol{y}}$ ).

Figure 7- Chronological sequence of criminal events. The time intervals are delimited by the tags of the time of last seen $t_{a}$ and the time of discovery $t_{b}$. When intervals overlap, it is not possible to determine which events happened first (e.g., $\left.t_{3}=t_{4}\right)$.

Figure 8 - If the aging curve is unknown (dots), the values obtained from two traces can be ordered in chronological order at the imperative condition that the aging kinetics are the same for the two traces and that the general evolution of the curve is known (increase or decrease). Measurement error must also be taken into account to insure the validity of the chronology.

Figure 9- Global framework to the situate traces in time. The date of fabrication, birth or last seen $\left(t_{a}\right)$, the date of discovery or seizure $t_{b}$ and the date of analysis $t_{c}$ are known or determined by the investigation. This information will then help extrapolate more or less precisely the dates of transfer of traces $\left(t_{x}\right.$ et $\left.t_{y}\right)$ or eventually a time interval for the deposition of a trace (e.g. trace y was left between 
$t_{a y}$ et $\left.t_{b y}\right)$. It is necessary to keep in mind that the object or person at the source of the traces also age with time. Moreover traces issued from different sources can to some extent also be chronologically ordered.

Table 1 - Selected practical applications in forensic science taken from the literature to illustrate the time tags dating approach

Table 2 - Selected practical applications in forensic science taken from the literature to illustrate the aging dating approach.

Table 3 - Selected practical applications in forensic science taken from the literature to illustrate the chronology dating approaches 


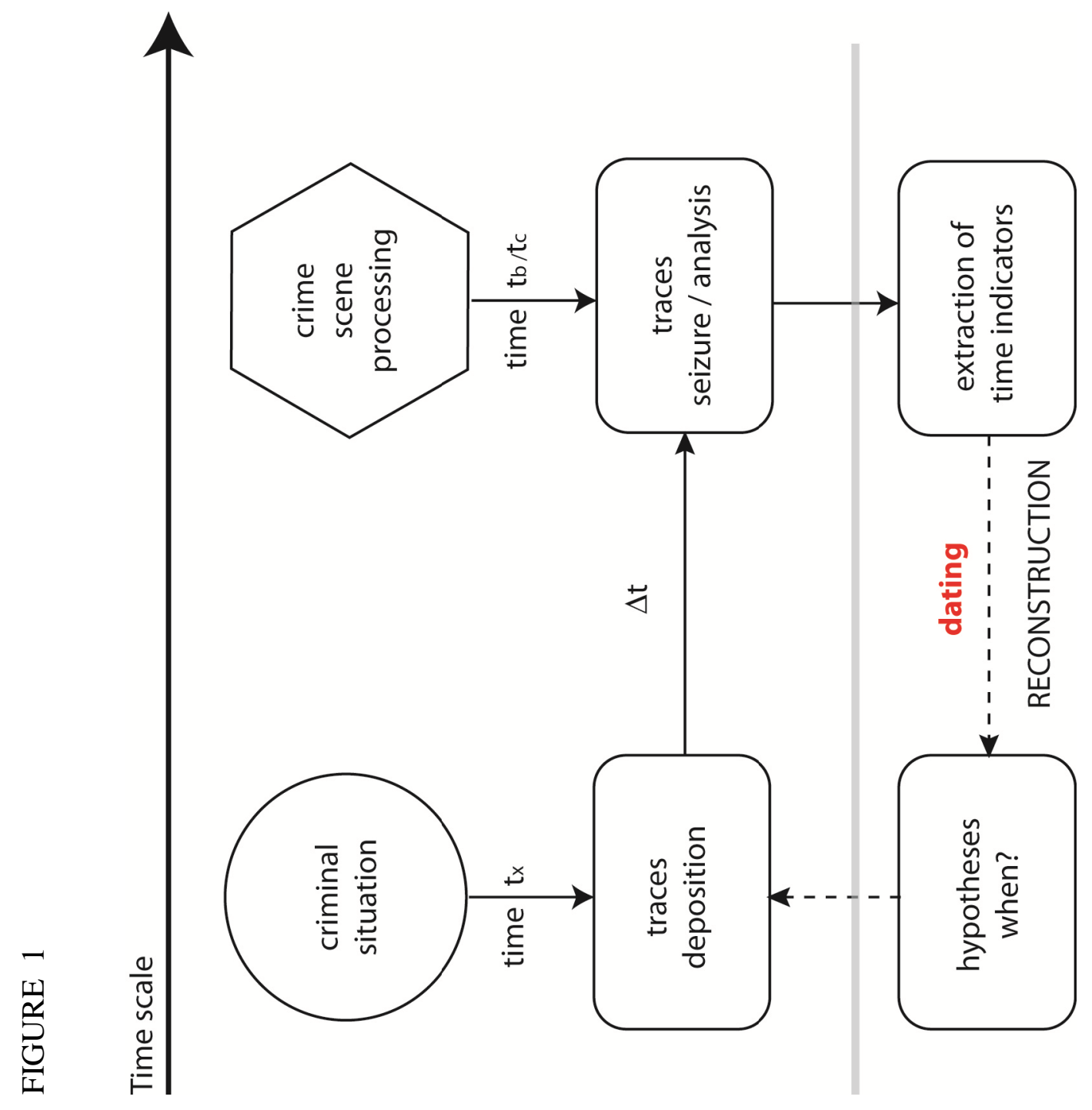


$\frac{0}{0}$

$\frac{1}{0}$

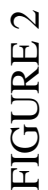

$\stackrel{\varepsilon}{E}$ 


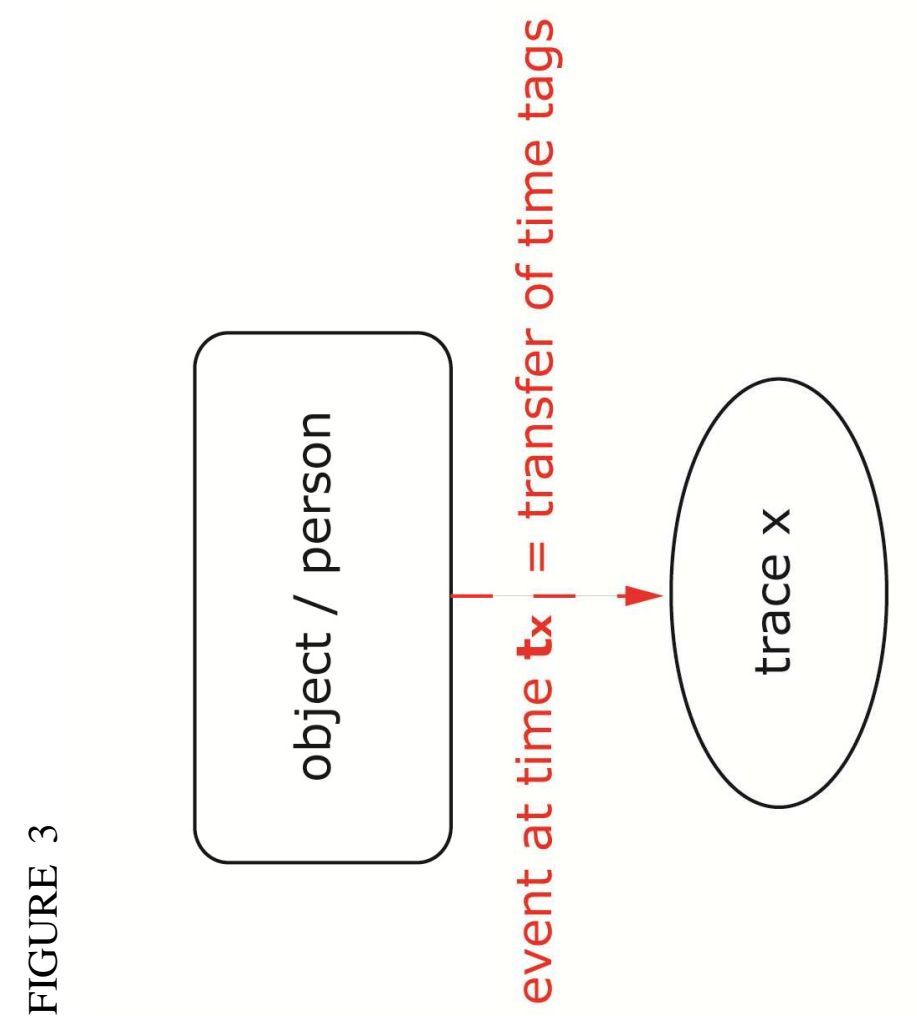




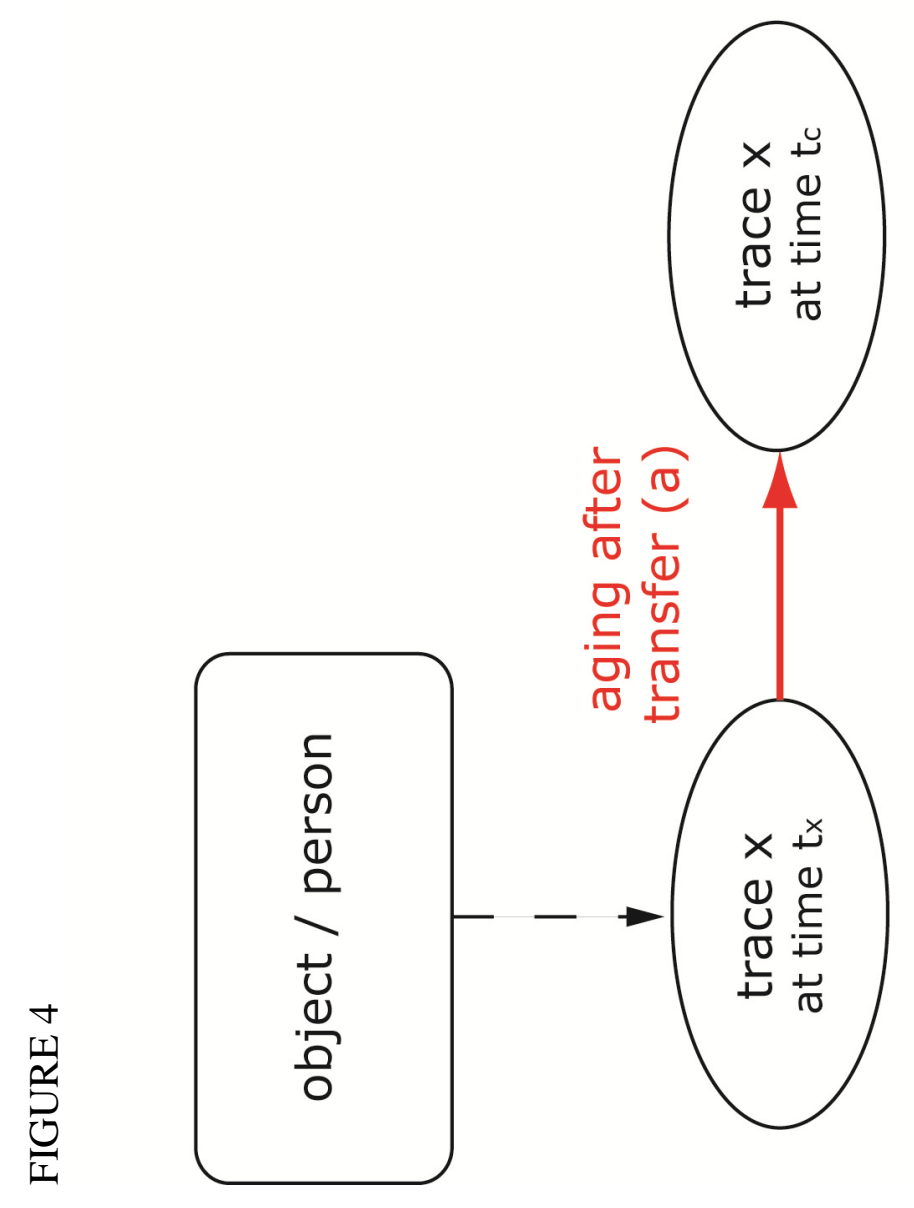




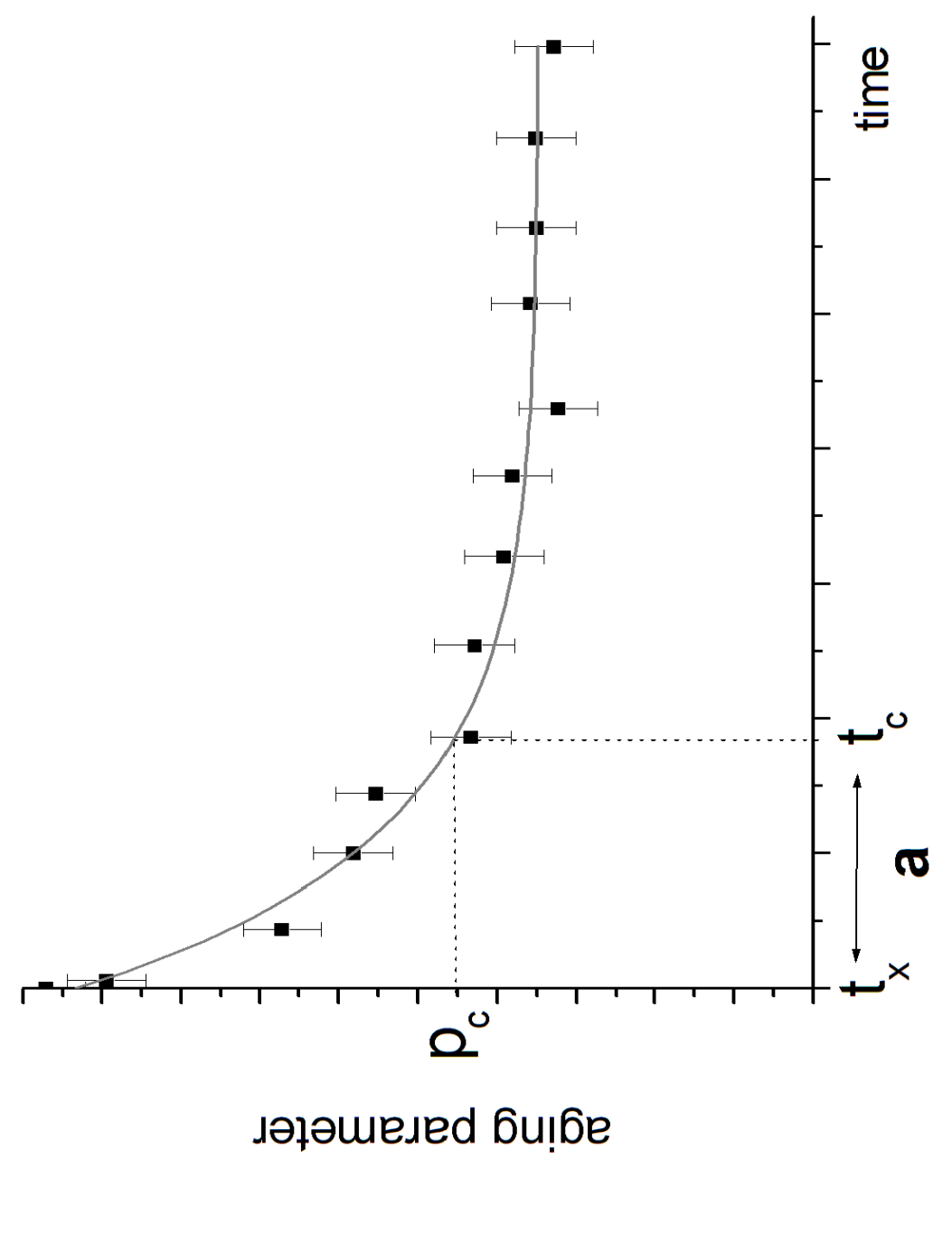




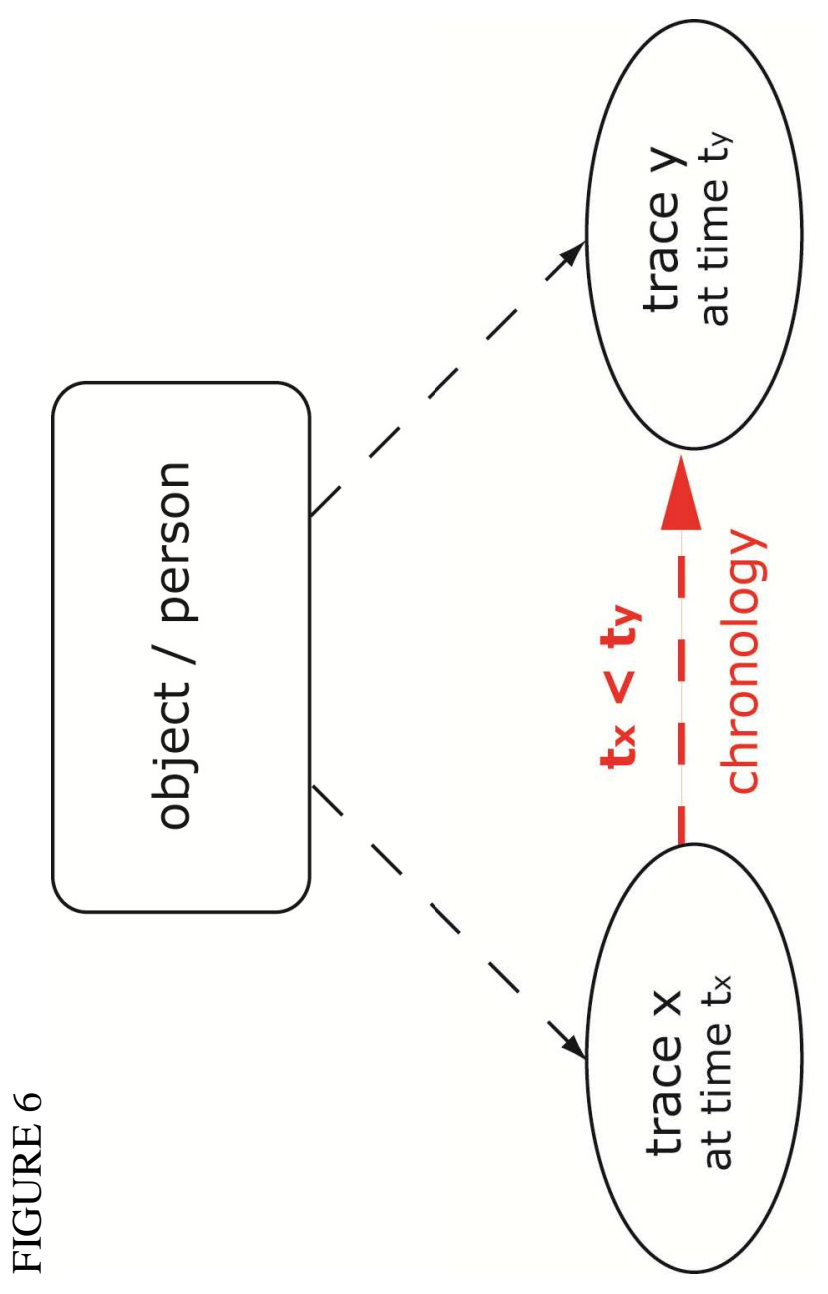




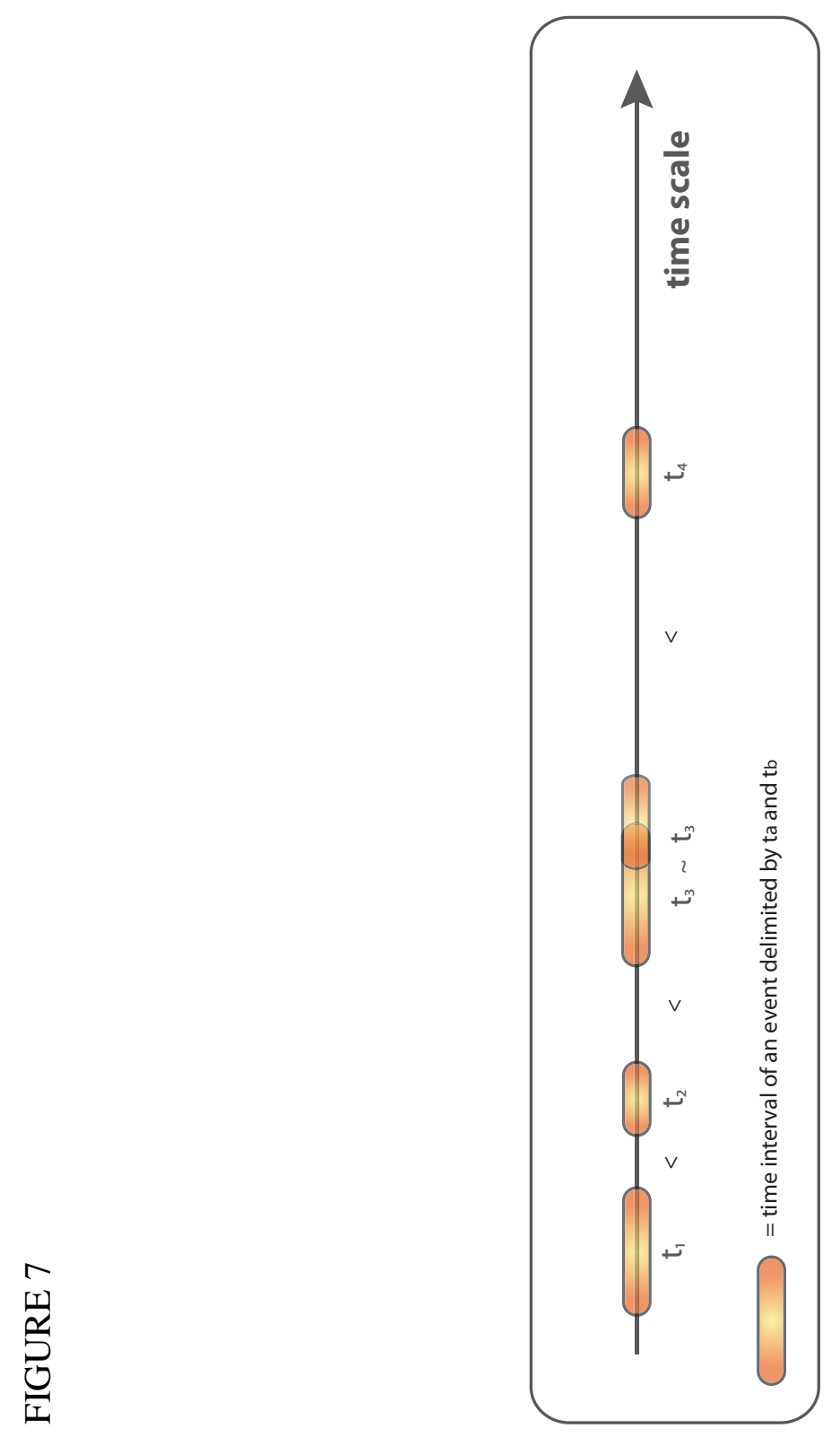




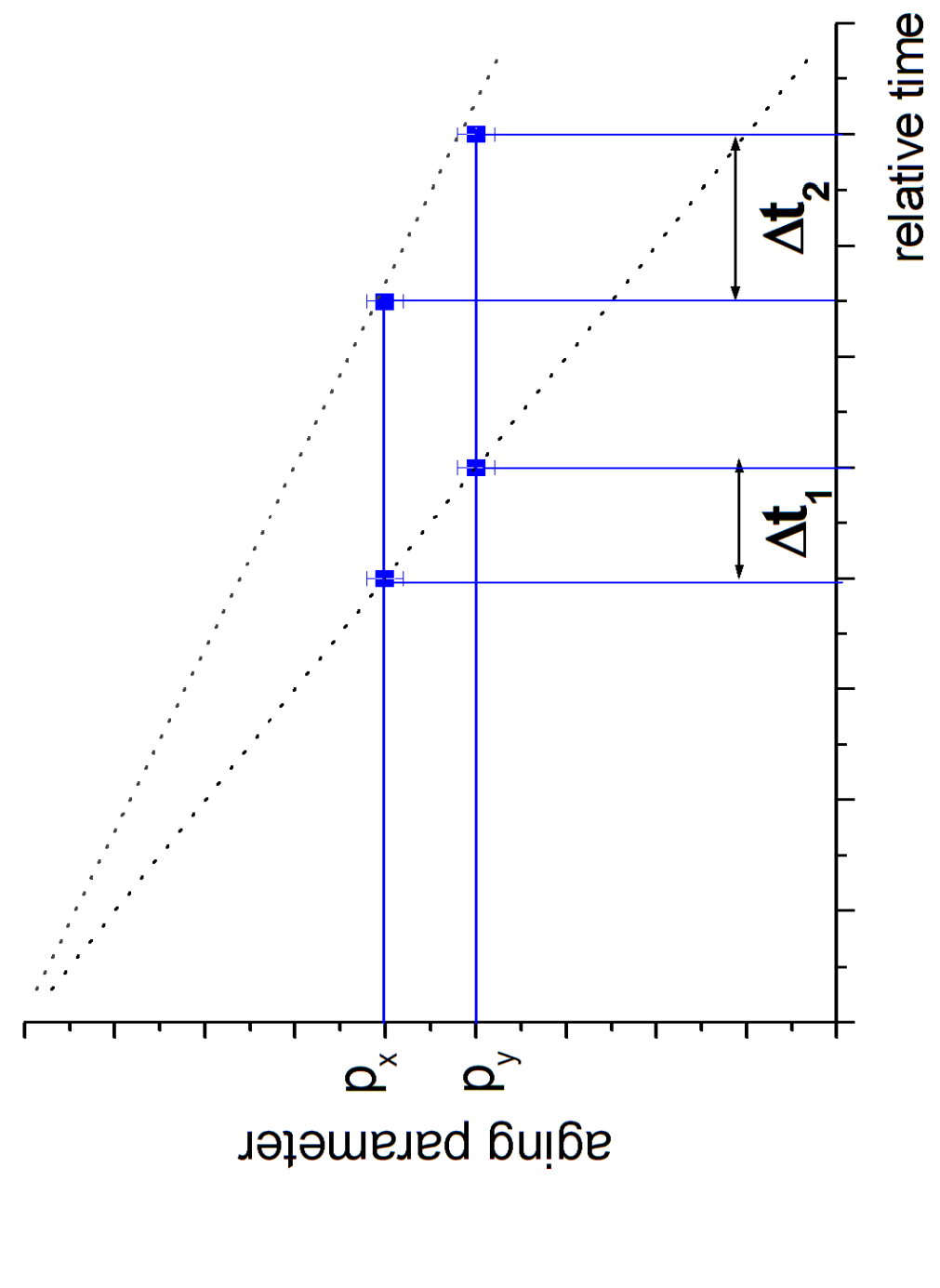




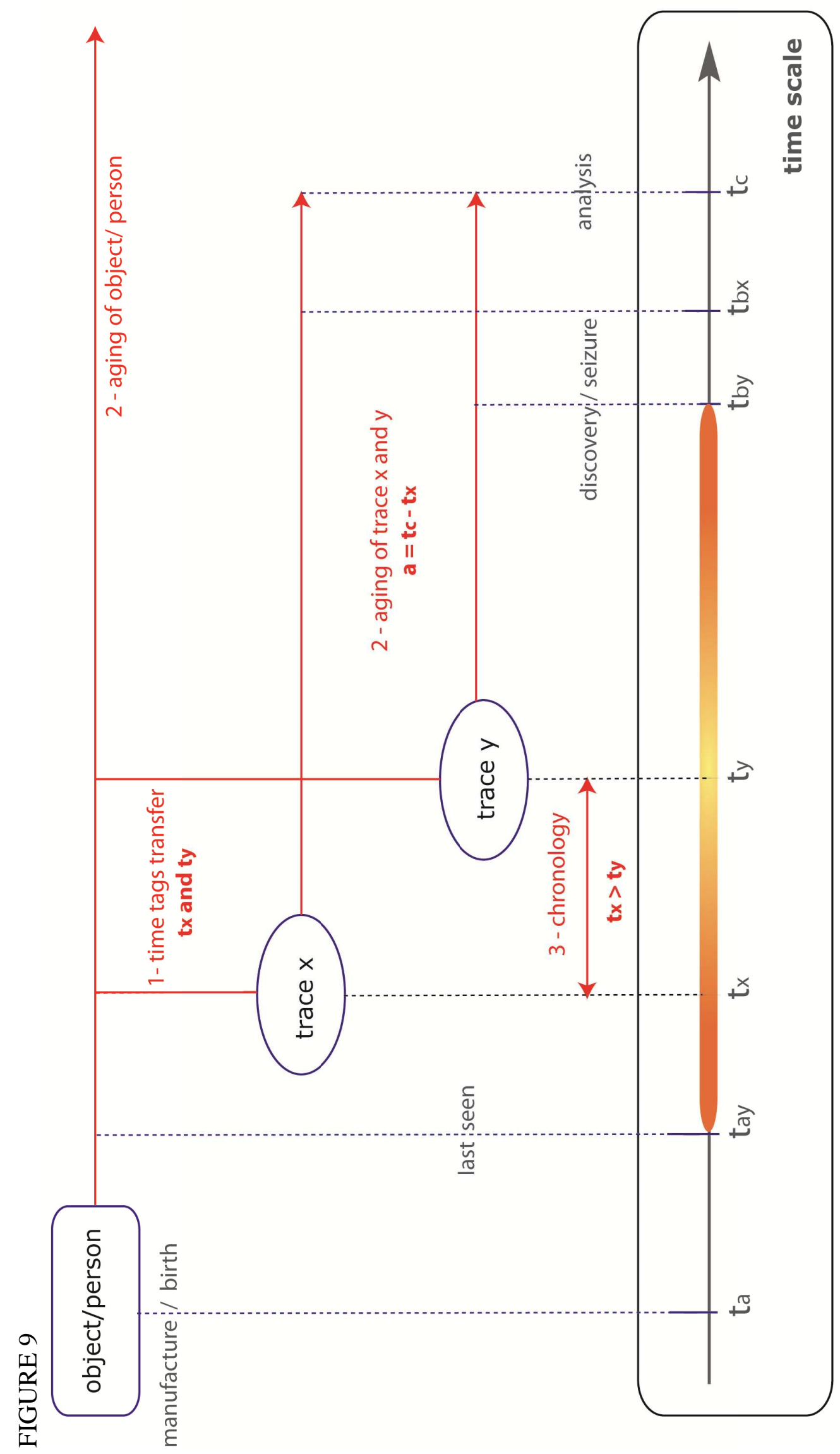





\section{1 - Time tags - Examples}

Numerical

\begin{tabular}{c} 
Punctual \\
$\mathbf{t}_{\mathbf{x}} \pm$ error \\
\hline Drug Seizure \\
When police services \\
seize drugs during an \\
investigation, they record \\
the time of seizure $\mathbf{t}_{\mathbf{x}}$ in a \\
database. This \\
information can be used \\
to highlight trafficking \\
patterns in time [18]
\end{tabular}

Fire alarm

When a fire alarm is
activated, this
information $\mathbf{t}_{\mathbf{x}}$ is
centralised and can be
used in the process of
dating the fire ignition

\begin{abstract}
Interval
\end{abstract}
$\mathbf{t}_{\mathbf{a}}<\mathbf{t}_{\mathbf{x}}<\mathbf{t}_{\mathrm{b}}$

Phone call

The time of a phone call

$$
\text { is delimited by the }
$$

beginning $\mathbf{t}_{\mathbf{a}}$ and end of

the call $\mathbf{t}_{\mathbf{b}}$. This

information is generally

combined with the space

and number called by a

specific phone card [16].

\section{Burglary}

Punctual

Contextual

Punctual
$\mathbf{t}_{\mathbf{x}} \pm$ error
Photography
A photography can be
dated (t $\mathbf{x}_{\mathbf{x}}$ ) by the content
of the picture (e.g., solar
direction, weather,
seasonal information,
objects and people)
[22]

Interval

$\mathbf{t}_{\mathbf{a}}<\mathbf{t}_{\mathbf{x}}<\mathbf{t}_{\mathrm{b}}$

The time of creation of

an ink entry can be

situated in a time interval

by the identification of

tags (at time $\mathbf{t}_{\mathbf{b}}$ )

introduced during the

manufacturing process

(at time $\mathbf{t}_{\mathbf{a}}$ ) [27]

The time of occurrence

of burglaries is generally

included between the

time the inhabitants left

their house $\mathbf{t}_{\mathbf{a}}$ and the

time of discovery $\mathbf{t}_{\mathbf{b}}$. This

impreciseness must be

taken into account when

the information is used

for intelligence,

The age of a person at the time of deposition $\left(\mathbf{t}_{\mathbf{x}}\right)$ of a blood spot can

theoretically be inferred

by determining the

telomere length in the

trace [25]

Paper

investigative or

evaluative purposes

[2]

The discovered diaries

were written on

fluorescent paper introduced on the market (at time $\mathbf{t}_{\mathbf{a}}$ ) after Hitler's death, thus highlighting an anachronism [24]

Table 1 - Selected practical applications in forensic science taken from the literature to illustrate the time tags dating approach 


\section{2 - Aging - Examples}

$$
\mathbf{t}_{\mathbf{x}}=\mathbf{t}_{\mathbf{c}}-\mathbf{a}
$$

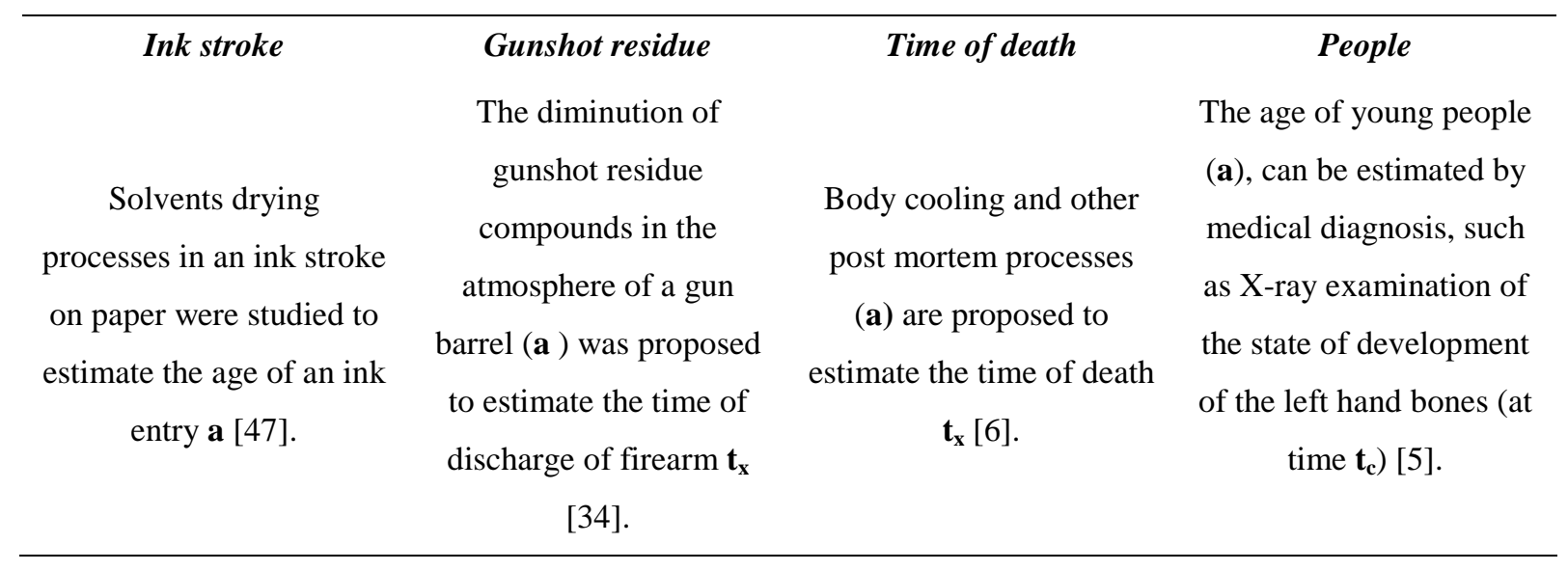

Table 2 - Selected practical applications in forensic science taken from the literature to illustrate the aging dating approach. 


\section{3 - Chronology - Examples}

\begin{tabular}{ccc} 
Superposition & Relative aging & Time tags \\
\hline Ink stroke & Gunshot residues & Fire alarm \\
& In a case where a man & Fire alarms activation (as \\
whe determination of the & from a double-barrelled & information) were \\
sequence of line crossing & shotgun. It was & calibrated and ordered in \\
can be determined by & determined that only one & time to reconstruct the \\
optical of physical & barrel was fired twice & chronology of events \\
examinations [42] & (supporting the murder & (start and development of \\
& hypothesis against the & fire, rescue actions of \\
& accident hypothesis) [50] & personal, etc.) [2] \\
\hline
\end{tabular}

Table 3 - Selected practical applications in forensic science taken from the literature to illustrate the chronology dating approaches 